\title{
Are Water-Soluble Natural Antioxidants Synergistic in Combination with $\alpha$-Tocopherol ?
}

\author{
Kazuyuki Hiramoto, Yukako MiUra, Goh OHNuki, \\ Tetsuta Kato and Kiyomi KIKUGAwA* \\ School of Pharmacy, Tokyo University of Pharmacy and Life Science \\ (1432-1 Horinouchi, Hachioji, Tokyo 192-0392, JAPAN)
}

Edited by H. Shimasaki, Teikyo Univ., and accepted April 10, 2002 (received for review March 25, 2002)

\begin{abstract}
Tocopherol, ascorbic acid, catechins ((+)-catechin, (-)-epicatechin, (-)epigallocatechin, (-)-epicatechin gallate and (-)-epigallocatechin gallate), furanones $(2,5$ dimethyl-4-hydroxy-3(2H)-furanone and 2-ethyl-4-hydroxy-5-methyl-3(2H)-furanone), pyrogallol, hydroxyhydroquinone and resveratrol donated hydrogen atoms to stable free radical 1,1-diphenyl-2-picrylhydrazyl (DPPH) in a biphasic solvent system. When ascorbic acid, (-)epicatechin gallate or (-)-epigallocatechin gallate was combined with $\alpha$-tocopherol, the mixtures donated hydrogen atoms more than those calculated. Most of these water-soluble antioxidants inhibited the formation of thiobarbituric acid-reactive substances in the radical initiator-induced oxidation of methyl linoleate in a homogeneous system. However, the water-soluble antioxidants except for ascorbic acid showed no significant synergistic antioxidant activities when they were combined with $\alpha$-tocopherol. In this system, ascorbic acid strongly inhibited $\alpha$-tocopherol decomposition, whereas other water-soluble antioxidants slightly. Interestingly, $\alpha$-tocopherol slightly inhibited decomposition of most of these water-soluble antioxidants. It is unlikely that water-soluble antioxidants except for ascorbic acid regenerate $\alpha$-tocopherol and acts as synergists in combination with $\alpha$-tocopherol.
\end{abstract}

Key words: 1,1-diphenyl-2-picrylhydrazyl, $\alpha$-tocopherol, water-soluble antioxidant, synergistic effect

\section{Introduction}

Synthetic lipid-soluble phenolic antioxidants, butyl hydroxyanisole (BHA), butylated hydroxytoluene (BHT) and propyl gallate are used to prevent peroxidation of edible fats and oils, and generally used in combination because of their excellent synergistic effects (1-4). Synergistic antioxidant effect between lipid-soluble $\alpha$-tocopherol (Toc) and water-soluble ascorbic acid (AsA) for cell membranes has been established (5-9), where Toc acts as a primary antioxidant and the resulting $\alpha$-tocopheryl radical then reacts with AsA to regen- erate Toc.

A wide variety of water-soluble plant polyphenolics including flavonoids and catechins, which originated from tea, fruits (for instance, apples) and vegetables (for instance, onions) are daily taken up. An average total daily consumption of flavonoids in the Netherlands has been estimated to be $23 \mathrm{mg}$ (10) that is more than the average daily intake of Toc (7-10 mg). In the in vitro studies, polyphenolics, flavonoids and catechins are shown to be powerful inhibitors of lipid peroxidation and scavengers of reactive oxygen species (11-20). Tea catechins supplemented to rats with diet are

\footnotetext{
* Correspondence to: Kiyomi KIKUGawA, School of Pharmacy, Tokyo University of Pharmacy and Life Science, 1432-1 Horinouchi, Hachioji, Tokyo 192-0392, JAPAN

E-mail: kikugawa@ps.toyaku.ac.jp.
} 
absorbed into blood (21) and prevent Toc decomposition in plasma and erythrocytes (22). Hydrogen donating capabilities of flavonoids (23) and tea catechins (24, 25) to stable free radical 1,1-diphenyl-2-picrylhydrazyl (DPPH) has been demonstrated.

The aim of the present study was to find whether water-soluble natural plant originated antioxidants synergistically act in combination with Toc. Tested antioxidants are tea catechins $((+)$-catechin $(\mathrm{C}),(-)$-epicatechin (EC), (-)-epigallocatechin (EGC), (-)-epicatechin gallate $(\mathrm{ECg})$ and (-)-epigallocatechin gallate $(\mathrm{EGCg}))$, furanones (2,5-dimethyl-4-hydroxy-3(2H)-furanone (DMHF) and 2-ethyl-4-hydroxy 5-methyl-3(2H)-furanone (HEMF)) contained in many foodstuffs as products of Maillard reaction (26), pyrogallol (PG) and hydroxyhydroquinone (HHQ) found in roasted coffee beans (27) and resveratrol in grapes. As well as AsA some of these antioxidants showed synergistic effects in hydrogen donation to DPPH, but the antioxidants except for AsA showed little synergistic activity in the formation of thiobarbituric acid-reactive substances (TBARS) in an azo compound-induced methyl linoleate (ML) oxidation system. While AsA strongly prevented decomposition of Toc, other antioxidants prevented slightly.

\section{Materials and Methods}

\subsection{Materials}

1,1-Diphenyl-2-picrylhydrazyl (DPPH), $\alpha$-tocopherol (Toc), 2,5-dimethyl-4 hydroxy-3(2H)-furanone (DMHF), 2-ethyl-4-hydroxy-5-methyl-3(2H)-furanone (HEMF) and methyl linoleate (ML) were obtained from Tokyo Chemical Industry (Tokyo, Japan). Ascorbic acid (AsA), hydroxyhydroquinone (HHQ) and 2,2'-azobis(2,4-dimethylvaleronitrile) (AMVN) were obtained from Wako Pure Chemical Industries (Osaka, Japan). $(+)$-Catechin (C), (-)-epicatechin (EC), (-)-epigallocatechin (EGC), (-)-epicatechin gallate (ECg) and (-)-epigallocatechin gallate (EGCg) were obtained from Funakoshi (Tokyo, Japan). Pyrogallol (PG) was obtained from Kanto Chemical Company (Tokyo, Japan). Resveratrol was from Sigma Chemical Company (St. Louis, MO, USA). Ethyl icosapentaenoate and ethyl docosahexaenoate were obtained from Nippon Chemical Feed Company (Tokyo, Japan).

\section{2 Donation of Hydrogen Atom to DPPH}

Donation of hydrogen atom to stable free radical DPPH (28) was conducted in a biphasic solvent system. Five milliliters of $n$-hexane containing $0.5 \mu \mathrm{mol} \mathrm{DPPH}$ and less than $0.1 \mu \mathrm{mol}$ Toc were mixed to $5.0 \mathrm{~mL} 0.1 \mathrm{M}$ phosphate buffer ( $\mathrm{pH} 7.4$ ) containing less than $0.1 \mu \mathrm{mol}$ each of water-soluble antioxidants in a $20-\mathrm{mL}$ glass tube with a screwed cap. The mixture was vigorously shaken at room temperature for $2.5 \mathrm{~h}$. The mixture was centrifuged at $3000 \mathrm{rpm}$ for $10 \mathrm{~s}$, and absorbance at 510 $\mathrm{nm}$ of $n$-hexane layer was monitored.

\subsection{Determination of Antioxidants by HPLC}

The concentration of antioxidants in the sample solutions was determined by high performance liquid chromatography (HPLC). HPLC was performed with a Shimadzu LC-6A pump (Kyoto, Japan) equipped with a column $(4.6 \mathrm{~mm}$ i.d. $\times 250 \mathrm{~mm})$ of Inertsil ODS-2 (GL Science Company, Tokyo, Japan) by using the following mobile phase at a flow rate of $1.0 \mathrm{~mL} / \mathrm{min}$, and the peaks were detected at the following wavelength in a Shimadzu SPD-6A detector (Kyoto, Japan). An aliquot of $50 \mu \mathrm{L}$ of the sample solution was injected. The mobile phase, detection wavelength and the retention time were: for Toc: methanol/glacial acetic acid/water (100: 1: 2, v/v/v), $290 \mathrm{~nm}, 19 \mathrm{~min}$; for EC: acetonitrile/ethyl acetate/ $0.05 \%$ phosphoric acid (12: 0.6: 45. $\mathrm{v} / \mathrm{v} / \mathrm{v}), 280 \mathrm{~nm}, 15 \mathrm{~min}$; for EGC: acetonitrile/ethyl acetate $/ 0.05 \%$ phosphoric acid (12: 0.6: 90, v/v/v), 280 nm, $5 \mathrm{~min}$; for ECg: the same mobile phase for EC, 280 $\mathrm{nm}, 9 \mathrm{~min}$; for EGCg: the same mobile phase for EGC, $280 \mathrm{~nm}, 6 \mathrm{~min}$; for DMHF: methanol/glacial acetic acid/water (15: $0.1: 85, \mathrm{v} / \mathrm{v} / \mathrm{v}), 280 \mathrm{~nm}, 6 \mathrm{~min}$; and for HEMF (the major isomer) : the same mobile phase for DMHF, $280 \mathrm{~nm}, 8 \mathrm{~min}$. The amount of each antioxidant in the sample solution was determined by comparing the peak area to that obtained from the standard antioxidant solution.

\subsection{Thiobarbituric Acid (TBA) Assay for ML Oxidation}

ML oxidation does not give malonaldehyde derivatives but other aldehyde derivatives (29). TBA assay was conducted in the presence of Fe ion to obtain effective coloration due to aldehyde derivatives other than malonaldehyde derivatives (30). Thus, to a $0.2 \mathrm{~mL}$ sample solution, $0.2 \mathrm{~mL} 8.1 \%$ sodium dodecylsulfate 
solution, $1.5 \mathrm{~mL} 20 \%$ acetic acid solution adjusted at pH 3.5 with $\mathrm{NaOH}, 0.25 \mathrm{~mL}$ water, $50 \mu \mathrm{L}$ of $0.8 \%$ BHT solution in glacial acetic acid, $2.0 \mathrm{~mL} 0.6 \%$ TBA solution, and finally $0.8 \mathrm{~mL} 6 \mathrm{mM} \mathrm{FeCl} 3$ solution were added. The mixture was kept at $4^{\circ} \mathrm{C}$ for $1 \mathrm{~h}$, and then heated at $100^{\circ} \mathrm{C}$ for $1 \mathrm{~h}$. Red pigment produced was extracted with $5.0 \mathrm{~mL} n$-butanol/pyridine $(15: 1, \mathrm{v} / \mathrm{v})$. Absorbance at $532 \mathrm{~nm}$ was measured. The amount of TBA-reactive substances (TBARS) was determined by comparing the absorbance with that obtained from the standard tetramethoxypropane at $10 \mu \mathrm{M}$.

\section{Results}

\subsection{Hydrogen Donating Capabilities of Water-soluble Antioxidants to DPPH}

Hydrogen donating capabilities of water-soluble natural antioxidants to DPPH were determined by conversion into $\mathrm{DPPH}_{2}$ in a biphasic solvent system composed of phosphate buffer/n-hexane $(1: 1, \mathrm{v} / \mathrm{v})$. Thus, 0.5 $\mu \mathrm{mol}$ DPPH and less than $0.1 \mu \mathrm{mol}$ of Toc, AsA, C, EC, EGC, ECg, EGCg, DMHF, HEMF, PG, HHQ or resveratrol were dissolved in $10 \mathrm{~mL}$ of the biphasic sol- vent system, and after shaking the mixture at room temperature the loss of DPPH in $n$-hexane layer was determined by the decrease of absorbance of DPPH at 510 nm.

The decreases in absorbance by Toc and the watersoluble antioxidants reached plateaus in the $2.5 \mathrm{~h}$-shaking of the biphasic solvent mixture. Time-courses of the decreases of DPPH are shown in Fig. 1. The amount of DPPH lost at the $2.5 \mathrm{~h}$ shaking was linearly increased with the antioxidant concentrations lower than $0.1 \mu \mathrm{mol}$ (data not shown). The amounts of DPPH lost by 1 mol antioxidant after $2.5 \mathrm{~h}$ shaking are listed in Table 1. All the antioxidants donated more than 1 mol hydrogen atom to DPPH. The hydrogen donating capabilities of the antioxidants were different by the antioxidants: Toc and AsA donated about $2.5 \mathrm{~mol}$ hydrogen atoms, catechins, resveratrol and PG 4-14 mol hydrogen atoms, and furanones and HHQ only $1 \mathrm{~mol}$ hydrogen atom. Catechins, especially ECg and EGCg with gallate esters, had the strongest hydrogen donating capabilities.

Synergistic hydrogen donating capabilities of watersoluble antioxidants in combination with Toc were

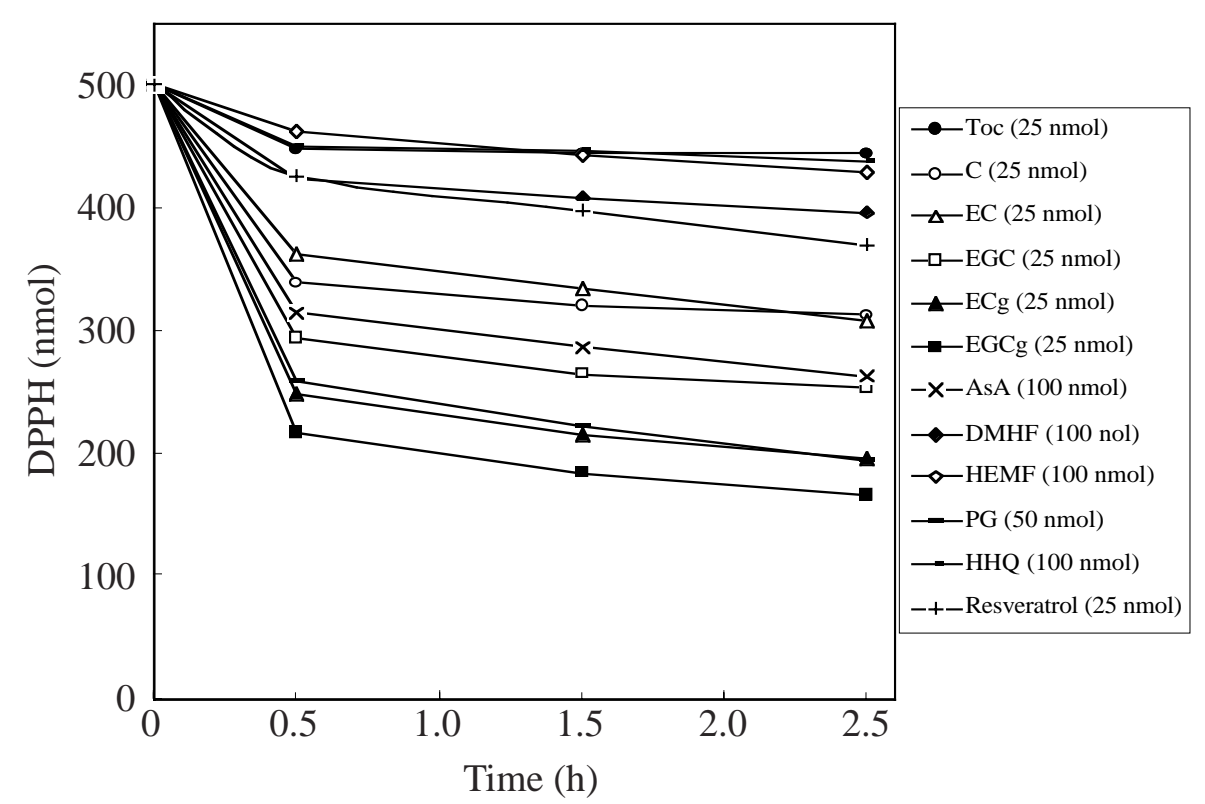

Fig. 1 Time Course of DPPH Loss by Antioxidants.

A $10 \mathrm{~mL}$ biphasic solvent system composed of $0.1 \mathrm{M}$ phosphate buffer $(\mathrm{pH}$ 7.4) $/ n$-hexane $(1: 1, \mathrm{v} / \mathrm{v})$ containing $0.5 \mu \mathrm{mol} \mathrm{DPPH}$ and antioxidants at the indicated concentration was shaken at room temperature for the indicated period. DPPH lost was determined by the decrease of absorbance at $510 \mathrm{~nm}$ of $n$-hexane layer. 
Table 1 Amount of DPPH Lost by 1 Mol of the Antioxidants.

\begin{tabular}{lc}
\hline & DPPH lost (mol) \\
\hline Toc & 2.4 \\
AsA & 2.5 \\
C & 7.4 \\
EC & 7.6 \\
EGC & 9.8 \\
ECg & 12.1 \\
EGCg & 13.3 \\
DMHF & 1.5 \\
HEMF & 1.1 \\
PG & 4.2 \\
HHQ & 1.1 \\
Resveratrol & 5.3 \\
\hline
\end{tabular}

A $10 \mathrm{~mL}$ biphasic solvent system composed of $0.1 \mathrm{M}$ phosphate buffer $(\mathrm{pH} 7.4) / n$ hexane $(1: 1, \mathrm{v} / \mathrm{v})$ containing $0.5 \mu \mathrm{mol} \mathrm{DPPH}$ and less than $0.1 \mu \mathrm{mol}$ antioxidant was shaken at room temperature for $2.5 \mathrm{~h}$. DPPH lost was determined by the decrease of absorbance at $510 \mathrm{~nm}$ of $n$-hexane layer.

examined. Hydrogen donating capabilities of the mixtures of Toc with the water-soluble antioxidants at the amount of each antioxidant varying and the total amount equal were examined. Representative profiles of DPPH loss in combinations Toc + AsA, Toc $+\mathrm{ECg}$ and Toc + EGCg are shown in Fig. 2. The observed DPPH losses in these combinations were larger than those calculated. Percentages of the observed DPPH loss at an equimolar ratio of Toc and the water-soluble antioxidant against the calculated loss are shown in Table 2. The results indicate that AsA, ECg, EGCg, HHQ and resveratrol showed slightly synergistic hydrogen donating capabilities in combination with Toc, whereas other antioxidants did not.

ML, ethyl icosapentaenoate and ethyl docosahexaenoate did not donate hydrogen atoms to DPPH under the conditions, and these fatty esters did not show any synergistic effects in combination with Toc in hydrogen donation to DPPH (data not shown). Combinations AsA + DMHF, AsA + HEMF, AsA + HHQ, AsA + PG, $\mathrm{DMHF}+\mathrm{HHQ}$, and DMHF + PG did not show any significant synergistic effects in hydrogen donation to DPPH (data not shown).

\subsection{Antioxidant Activities of the Water- soluble Antioxidants in the AMVN Induced Oxidation of ML}

Inhibitory effects of the water-soluble antioxidant alone and that combined with Toc on the ML oxidation induced by radical initiator AMVN in a homogeneous system was investigated. Thus, to a solution of tertbutanol/methanol containing $60 \mathrm{mM} \mathrm{ML}$ and $10 \mathrm{mM}$ AMVN, $30 \mu \mathrm{M}$ Toc alone, $30 \mu \mathrm{M}$ water-soluble antioxidant alone, or combined mixture $30 \mu \mathrm{M}$ Toc $+30 \mu \mathrm{M}$ water-soluble antioxidant was added, and the mixture
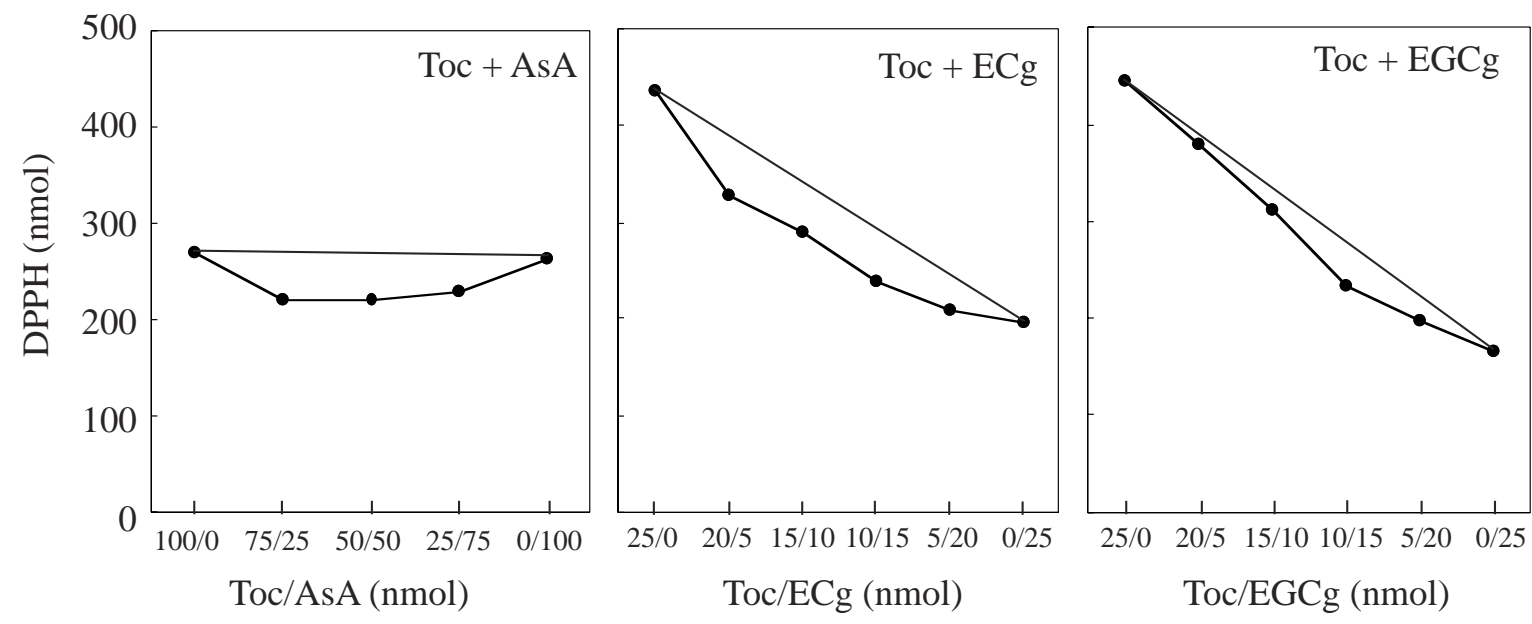

Fig. 2 Loss of DPPH by Toc Combined with AsA, ECg or EGCg.

A biphasic solvent mixture containing $0.5 \mu \mathrm{mol} \mathrm{DPPH}$, and combined Toc+AsA at a total amount of 0.1 $\mu \mathrm{mol}$, combined Toc + ECg at a total amount of $0.025 \mu \mathrm{mol}$, or combined Toc + EGCg at a total amount of $0.025 \mu \mathrm{mol}$ was shaken at room temperature for $2.5 \mathrm{~h}$. DPPH lost was determined by the decrease of absorbance at $510 \mathrm{~nm}$ of $n$-hexane layer. 
Table 2 Synergistic DPPH Loss in Combination of Toc with Watersoluble Antioxidant.

\begin{tabular}{ccc}
\hline $\begin{array}{c}\text { Water-soluble } \\
\text { antioxidant }\end{array}$ & $\begin{array}{c}\text { Total amount of Toc and } \\
\text { water-soluble antioxidant } \\
(\mu \mathrm{mol})\end{array}$ & $\begin{array}{c}\text { Observed DPPH loss at an } \\
\text { equimolar amount of Toc and } \\
\text { water-soluble antioxidant } \\
\text { (percent of the calculated loss) }\end{array}$ \\
\hline AsA & 0.1 & 122 \\
C & 0.025 & 100 \\
EC & 0.025 & 100 \\
EGC & 0.025 & 111 \\
ECg & 0.025 & 132 \\
EGCg & 0.025 & 117 \\
DMHF & 0.1 & 100 \\
HEMF & 0.1 & 102 \\
PG & 0.05 & 108 \\
HHQ & 0.1 & 120 \\
Resveratrol & 0.025 & 127 \\
\hline
\end{tabular}

A biphasic solvent system containing $0.5 \mu \mathrm{mol} \mathrm{DPPH}$, and combined Toc and watersoluble antioxidant at the total amount indicated was shaken at room temperature for $2.5 \mathrm{~h}$. DPPH lost was determined by the decrease of absorbance at $510 \mathrm{~nm}$ of $n$ hexane layer. Percentages of observed DPPH loss at an equimolar ratio of Toc and water-soluble antioxidant against the calculated loss were obtained.

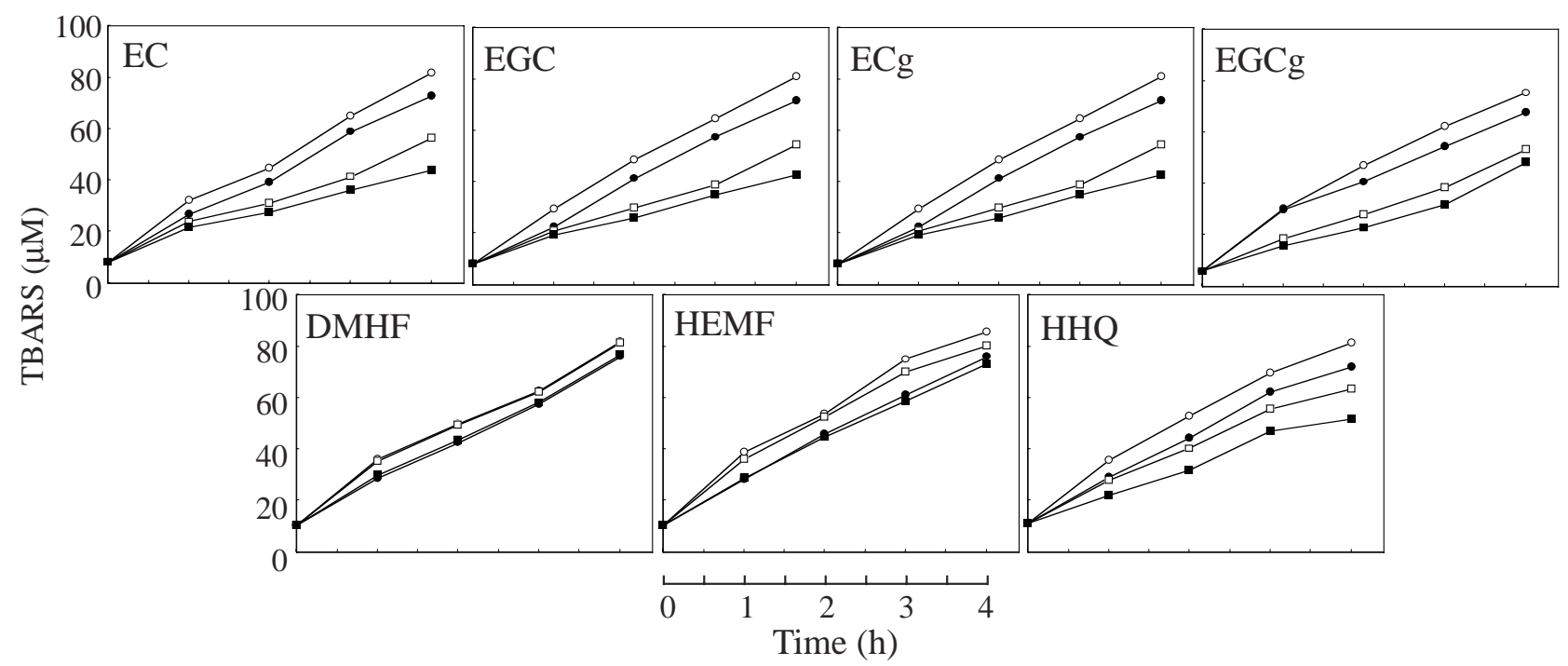

Fig. 3 Time Course of the AMVN-induced TBARS Formation in ML Oxidation in the Presence of Antioxidants. A solution of $60 \mathrm{mM}$ ML and $10 \mathrm{mM}$ AMVN, with none $(\bigcirc), 30 \mu \mathrm{M}$ Toc $(\bigcirc), 30 \mu \mathrm{M}$ water-soluble antioxidant $(\square)$, and combined $30 \mu \mathrm{M}$ Toc $+30 \mu \mathrm{M}$ water-soluble antioxidant $(\square)$, in tert-butanol/methanol (3:1, v/v) was incubated at $37^{\circ} \mathrm{C}$ under stirring. TBARS were measured as described in the Materials and methods section.

was kept at $37^{\circ} \mathrm{C}$ for $4 \mathrm{~h}$ under stirring. Time course of the increase of the degree of ML oxidation was followed by measurement of TBARS by the TBA assay in the presence of $\mathrm{Fe}$ ion (Fig. 3). In the absence of antioxidants $(\bigcirc)$, the amount of TBARS increased and reached about $80 \mu \mathrm{M}$ after $4 \mathrm{~h}$. In the presence of Toc alone $(\mathbf{)})$, the amounts of TBARS formed were decreased to only $80-90 \%$. In the presence of each of the water-soluble antioxidants $(\square), \mathrm{EC}, \mathrm{EGC}, \mathrm{ECg}$, EGCg and HHQ prevented the formation of TBARS 
more effectively than Toc did, but DMHF and HEMF less effectively than Toc. In combination of Toc with the water soluble antioxidants ( $\square$ ), no significant synergistic antioxidant activity but additive activity was observed.

\section{3·3 Prevention of Toc Decomposition by the Water-soluble Antioxidants during the AMVN-induced Oxidation of ML}

Protective effect of the water-soluble antioxidants on the decomposition of Toc during the AMVN-induced ML oxidation was examined. Fig. 4 shows time course of the decomposition of Toc in the presence of the water-soluble antioxidants. In the mixture of Toc without added water-soluble antioxidant, Toc was decreased linearly depending on the incubation time, and completely disappeared after $100 \mathrm{~min}$. In the mixture of Toc with AsA, Toc was completely protected during the oxidation period for $180 \mathrm{~min}$, and then gradually decreased. In the mixture of Toc + HHQ, EGC or EGCg, Toc was decomposed gradually from the start, but moderately prevented. In the mixture of Toc $+\mathrm{EC}$, ECg, DMHF or HEMF, Toc was not at all protected from decomposition. The results indicate that AsA was the strongest protector of Toc, but other water-soluble antioxidants were much less effective protectors.
Time course of the decrease of water-soluble antioxidants in combination with Toc was followed (Fig. 5). It was found that the water-soluble antioxidants, EC, EGC, ECg, EGCg, DMHF and HEMF, were protected from decomposition by Toc.

\section{Discussion}

Pronounced synergistic antioxidant effects between phenolic compounds and certain acidic organic compounds in peroxidation of edible fats and oils have been described (1). These active acidic synergists are effective to chelate metal ions, which could give rise to the theory that their activity is that of metal chelation. On the other hand, synthetic lipid-soluble phenolic antioxidants, BHA, BHT and propyl gallate are frequently used in combination to prevent peroxidation of fats and oils because of their excellent synergistic effects (2-4). Hydrogen donating capabilities of BHT, BHA and mixtures of them to DPPH have been compared (31). BHA donates 0.75-1.2 hydrogen atoms and BHT donates much less hydrogen atom, whereas synergistic hydrogen donation ( 2.78 hydrogen atoms) is observed in combination BHA + BHT in an organic solvent system. BHA reacts with 2 mol DPPH to form a stable intermediate, which reacts with $\mathrm{BHT}$ to regenerate $\mathrm{BHA}$ with

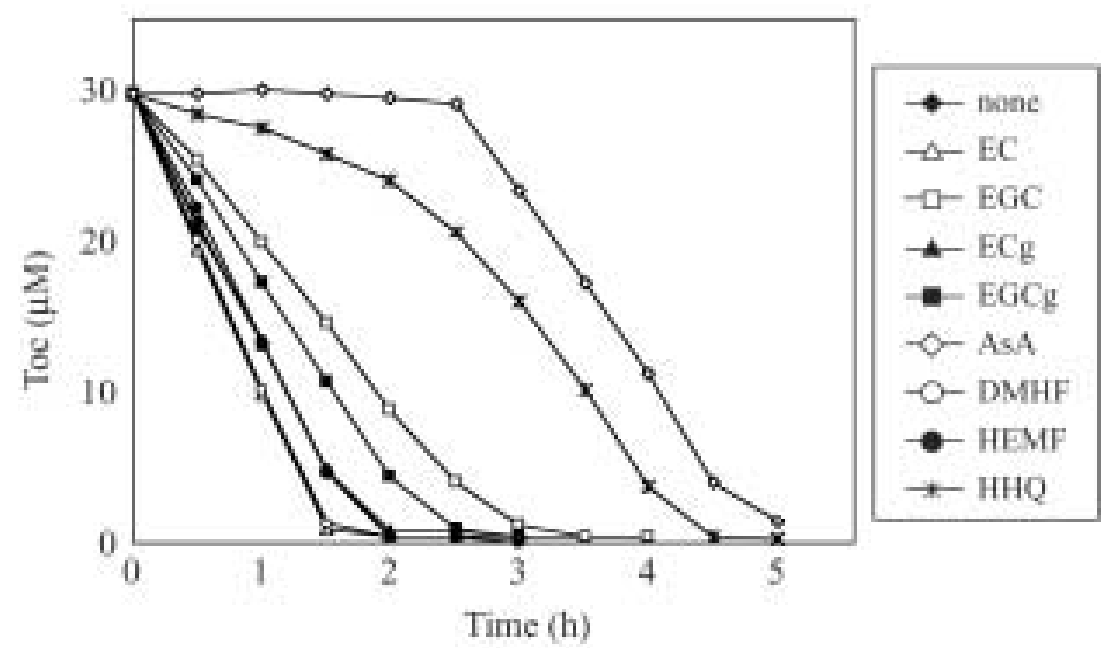

Fig. 4 Time Course of the Decrease of Toc in the Presence of Water-soluble Antioxidant during the AMVN-induced Oxidation of ML.

A mixture of $60 \mathrm{mM}$ ML, $3 \mathrm{mM}$ AMVN, $30 \mu \mathrm{M}$ Toc and $30 \mu \mathrm{M}$ watersoluble antioxidant in tert-butanol/methanol $(3: 1, \mathrm{v} / \mathrm{v})$ was incubated at $37^{\circ} \mathrm{C}$ under stirring. The concentration of Toc was determined by HPLC as described in the Materials and methods section. 


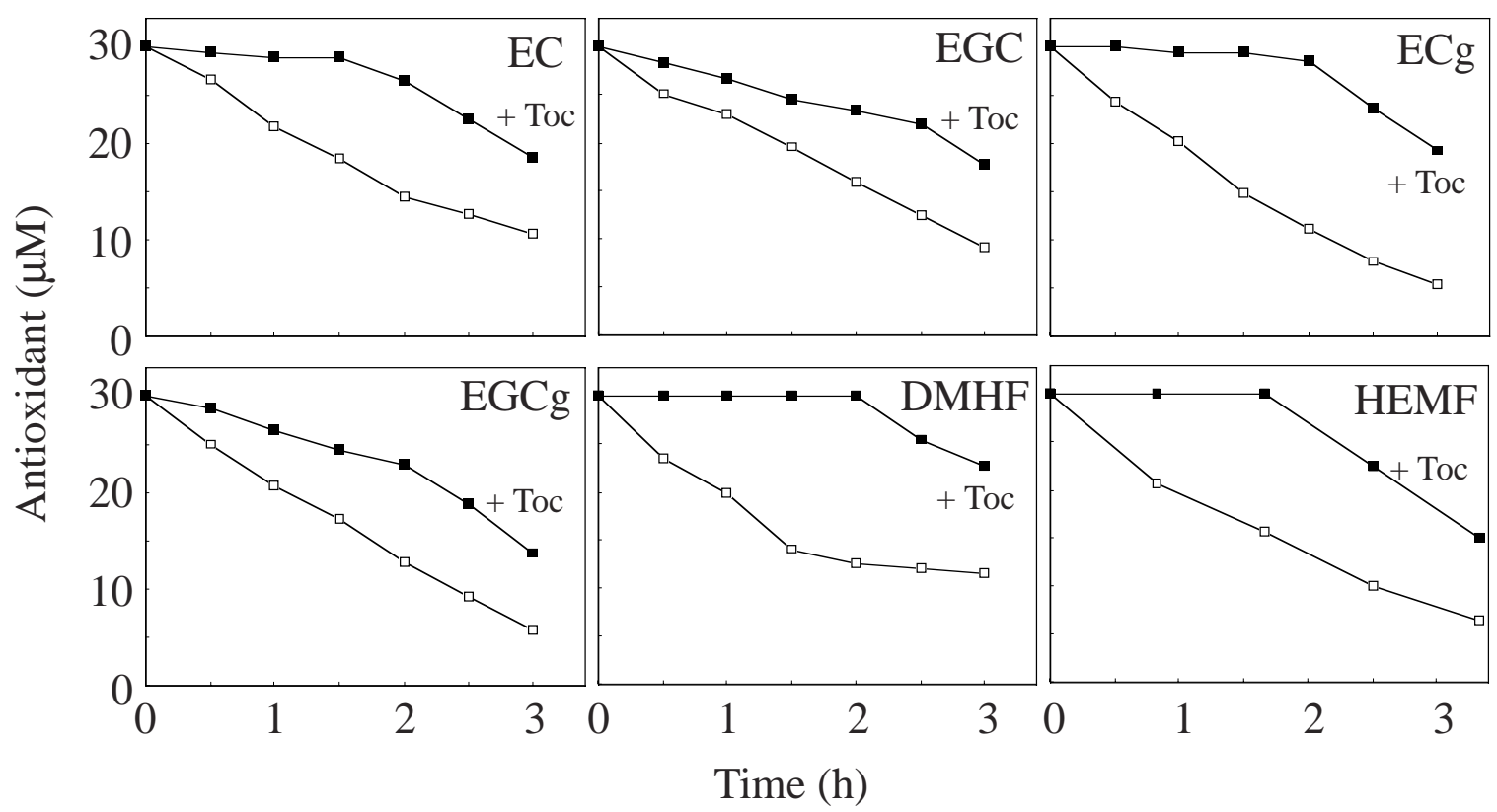

Fig. 5 Time Course of the Decrease of Water-soluble Antioxidants in the Presence of Toc during the AMVNinduced Oxidation of ML.

A mixture of $60 \mathrm{mM}$ ML, $10 \mathrm{mM}$ AMVN, and $30 \mu \mathrm{M}$ water-soluble antioxidant in the presence of $30 \mu \mathrm{M}$ Toc in tert butanol/methanol $(3: 1, \mathrm{v} / \mathrm{v})$ was incubated at $37^{\circ} \mathrm{C}$ under stirring. The concentration of each antioxidant was determined by HPLC as described in the Materials and methods section.

enhanced oxidation of BHT. This process may be associated with the synergism between BHA and BHT in hydrogen donation to DPPH, and thus to peroxy radicals of fats and oils. Catalytic activation of the hydrogen donating capability of inactive BHT by tocopherols is also shown (32).

Synergistic antioxidant activity between Toc and AsA has been shown in a trichloromethylperoxy radical-induced system, where Toc acts as the primary antioxidant and the resulting $\alpha$-tocopheryl radical then reacts with AsA to regenerate Toc (5). $\alpha$-Tocopheryl radical generated by DPPH disappeared rapidly when it is mixed with AsA (6). When either Toc or AsA alone is used in the azo compound induced ML oxidation system, they disappear linearly with time, whereas when both of them are used AsA is consumed first and Toc is consumed after AsA has disappeared, suggesting that Toc scavenges the peroxy radical of ML more quickly than AsA, and that the $\alpha$-tocopheryl radical reacts with AsA to regenerate Toc (7). Similar observations using liposome has been demonstrated (8). In these systems, oxygen consumption starts with an induction period after Toc had been completely decomposed. The coop- erative interaction between Toc and AsA in suppression of peroxidation of membrane phospholipids as assessed by the TBARS formation has been shown (9).

In the present study, synergistic antioxidant capabilities of water-soluble natural antioxidants in combination with Toc was examined. It was found that as well as AsA some of the water-soluble antioxidants exhibited synergistic hydrogen donation activities when combined with Toc in a biphasic system. However, none of the antioxidants except for AsA showed synergistic effect in combination with Toc when the TBARS formation in the radical initiator-induced ML oxidation was examined.

While AsA strongly protected Toc decomposition or regenerated Toc, most of other water-soluble antioxidants moderately or little protected Toc decomposition in the radical-initiator induced ML oxidation system. In constant, most of the water-soluble antioxidants except for AsA were protected from decomposition by Toc. Unlike AsA, other water-soluble antioxidants may not act synergistically with Toc in vivo membrane systems, where Toc is located in lipid bilayers of the cell membranes and the water-soluble antioxidants are pre- 


\section{K. Hiramoto, Y. Miura, G. Ohnuki et al.}

sent in the water-phase. Nevertheless, the antioxidants may be active to prevent lipid peroxidation by themselves, to chelate metal ions and scavenge reactive oxygen species in the in vivo water-phase (33).

\section{Acknowledgment}

This work was supported in part by a Grant for Private Universities provided by Japan Private School Promotion Foundation.

\section{References}

1. Lundberg, W.O. (1961) Autoxidation and Antioxidants, Vol. 1, Interscience, New York.

2. Gearhart, W.H. and Stukey, B.N. (1955) J. Am. Oil Chem, Soc., 32, 386-390.

3. Ingold, K.U. (1961) Chem. Rev., 61, 563-589.

4. Stucky, B.N. (1968) Handbook of Food Additives (Furia, T.E., ed.) Chemical Rubber Company, Cleveland, Ohio.

5. Packer, J.E., Slater, T.F. and Wilson, R.L. (1979) Nature, 278, 737-738

6. Niki, E., Tsuchiya, J., Tanimura, R. and Kamiya,Y. (1982) Chem. Lett., 789-792.

7. Niki, E., Saito, T., Kawakami, A. and Kamiya, Y. (1984) J. Biol. Chem., 259, 4177-4182.

8. Doba, T., Burton, G.W. and Ingold, K.U. (1985) Biochim. Biophys. Acta., 835, 298-303.

9. Leung, H.-W., Vang, M.J. and Mavis, R.D. (1981) Biochim. Biophys. Acta., 664, 266-272.

10. Keli, S.O., Hertog, M.G., Feskens, E.J. and Kromhout, D. (1996) Arch. Int. Med., 156, 637-642.

11. Baumann, J., Bruschhausen, F.V. and Wurm, G. (1980) Prostaglandins, 20, 627-639.

12. Robak, J. and Gryglewski, J. (1988) Biochem. Pharmacol., 37, $837-841$

13. Halliwell, B. and Gutteridge, M.C. (2000) Free Radicals in Biology and Medicine, 3rd edn, Oxford University Press, Inc., New York. pp 229-231.
14. Rice-Evans, C., Miller, N.J., Bowell, P.G., Bramley, P.M. and Pridham, J.B. (1995) Free Rad. Res., 22, 375-383.

15. Lea, C.H. and Swoboda, P.T.A. (1957) Chem. Indust., 10731074.

16. Hara, M. (1990) New Food Industry, 32, 33-38.

17. Hatano, T., Edamatsu, R., Hiramatsu, M., Mori, A., Fujita, Y., Yamashita, T., Yoshida, T. and Okuda, T. (1989) Chem. Pharm. Bull., 37, 2016-2021.

18. Namiki, M. and Osawa, T. (1986) Basic Life Sci., 39, 131-141.

19. Fujita, Y. (1987) Yakugaku Zasshi, 107, 17-22.

20. Fujita, Y. (1988) Yakugaku Zasshi, 108, 528-537.

21. Okushio, K., Matsumoto, N., Kohri, T., Suzuki, M., Nanjo, F. and Hara, Y. (1996) Biol. Pharm. Bull., 19, 326-329.

22. Nanjo, F., Honda, M., Okushio, K., Matsumoto, N., Ishigaki, F., Ishigami, T. and Hara, Y. (1993) Biol. Pharm. Bull., 16, 11561159.

23. Ratty, A.K., Subamoto, J. and Das, N.P. (1988) Biochem. Pharmacol., 37, 989-995.

24. Yoshida, T., Mori, K., Hatano, T., Okumura, T., Uehara, K., Komazoe, I., Fujita, Y. and Okuda, T. (1989) Chem. Pharm. Bull., 37, 1919-1921.

25. Hatano, T., Edamatsu, R., Hiramatsu, M., Mori, A., Fujita, Y., Yamashita, T., Yoshida, T. and Okuda, T. (1989) Chem. Pharm. Bull., 37, 2016-2021.

26. Kikugawa, K., Hiramoto, K. and Kato, T. (1998) Recent Res. Devel. In Agric. and Food Chem., 2, 237-257.

27. Hiramoto, K., Li, X., Makimoto, M., Kato, T. and Kikugawa, K. (1998) Mutattion Res., 419, 43-51.

28. Blois, M.S. (1958) Nature, 181, 1199-1200.

29. Kosugi, H., Kojima, T. and Kikugawa, K. (1991) J. Am. Oil Chem. Soc., 68, 51-55.

30. Kikugawa, K., Kojima, T., Yamaki, S. and Kosugi, H. (1992) Anal. Biochem., 202, 249-255.

31. Kurechi, T., Kikugawa, K. and Kato, T. (1980) Chem. Pharm. Bull., 28, 2069-2093.

32. Boguth, W., Reppes, R. and Zell, R. (1970) Int. Z. Vit. Forshung, 40, 323-333.

33. Morel, I., Lescoat, G., Cillarad, P. and Cillrad, J. (1994) Methods Enzymol., 234, 437-443. 